\title{
Strategi Penerapan Standar Nasional Indonesia Biskuit (SNI 2973:2011) bagi Industri Kecil Menengah
}

\author{
Srategy of Applying National Standard of Indonesia Biscuit (SNI 2973:2011) \\ for Small Medium Enterprises \\ Syaiful ${ }^{1 *}$, Hartrisari Hardjomidjojo ${ }^{2 \sharp}$, dan Eko Ruddy Cahyadi ${ }^{3 \sharp}$ \\ ${ }^{1}$ Program Studi Pengembangan Industri Kecil dan Menengah, Sekolah Pascasarjana IPB \\ ${ }^{2}$ Departemen Teknologi Industri Pertanian, Fakultas Teknologi Pertanian, IPB \\ ${ }^{3}$ Departemen Manajemen Fakultas Ekonomi dan Manajemen, IPB \\ Jl. Kamper Kampus IPB Dramaga Bogor 16680
}

\begin{abstract}
ABSTRAK
Badan Standardisasi Nasional (BSN) pada tanggal 22 Desember 2011 telah menetapkan SNI 2973:2011 Biskuit melalui SK Kepala BSN No.242/KEP/BSN/12/2011. Ruang lingkup produk dalam SNI 2973:2011 adalah Biskuit, Krekers, Wafer, Pai, dan Kukis. Sampai saat ini jumlah industri yang yang menerapkan SNI Biskuit masih rendah, dari 595 merek produk biskuit yang sudah terdaftar di Badan Pengawas Obat dan Makanan (BPOM)) hanya 28 merk biskuit yang mendapatkan sertifikat tanda Standar Nasional Indonesia (SNI). Pengembangkan strategi penerapan SNI Biskuit bagi Industri Kecil Menengah (IKM) adalah untuk memberikan masukan bagi IKM biskuit dalam menerapkan SNI, serta masukan kepada instansi teknis terkait (Kementerian Perindustrian, kemenkop dan UKM, Pemerintah daerah, BSN) dan pihak yang terkait dalam melakukan pembinaan terkait penerapan standar produk biskuit bagi IKM. Hasil penilaian terhadap kesiapan lima IKM dalam menerapkan SNI 2973:2011 Biskuit IKM A 97,4\%; IKM B 84,5\%; IKM C 83,6\%; IKM D 62,9\%; dan IKM E 71,4\%. Pengelompokan kelima IKM dengan menggunakan analisa statistik diperoleh empat kelompok IKM berdasarkan tingkat kesiapannya dalam menerapkan SNI Biskuit, yaitu pertama kelompok yang siap dalam menerapkan SNI Biskuit (IKM A) yang berada pada zona 1; kedua kelompok yang cukup siap dalam menerapkan SNI Biskuit (IKM B dan C) yang berada pada zona 2; ketiga kelompok IKM yang kurang siap dalam menerapkan SNI Biskuit (IKM E) yang berada pada zona 3; keempat kelompok IKM yang tidak siap dalam menerapkan SNI Biskuit (IKM D) yang berada pada zona 4. Strategi yang direkomendasikan bagi keempat kelompok IKM dengan menggunakan diagram Ishikawa yang berfokus pada faktor internal dan eksternal sumber daya terendah di setiap kelompok IKM.
\end{abstract}

Kata kunci: biskuit, BSN, IKM, strategi penerapan SNI, zona

ABSTRACT

BSN on December 22, 2011 has stipulated SNI 2973: 2011 Biscuit through the Decree of the Head of BSN No.242/KEP/BSN/12/2011, scope of products in SNI 2973: 2011 are Biscuits, Krekers, Wafers and Pies, Kukis. Until now the number of industries that apply SNI Biscuits is still low from 595 brands of biscuit products that have been registered in BPOM (BPOM, 2017) only 28 brands of biscuits that have received the certificate of SNI (BSN, 2018). Developing strategies to apply SNI Biscuit for SME is to increase applying SNI, as well as input to related technical institution and related party in conducting coaching related to application SNI products for SME. The results of the assessment of the readiness of the five SME in implementing SNI 2973: 2011 Biscuits respectively as follows: SME A is 97.4\%; SME B is $84.5 \%$; SME C of $83.6 \%$; SME D of $62.9 \%$; and SME E of $71.4 \%$. The grouping of the five SME using statistical analysis four SME groups based on their level of readiness in applying Biscuit SNI, namely the first group that is ready to apply the Biscuit SNI (SME A) which is in zone 1; the two groups are quite ready in applying the Biscuit SNI (SME B and C) in zone 2; the three groups of SME that are less prepared

\footnotetext{
*) Korespondensi:

Jl.Temulawak No 24 Perum Atsiri Permai, Ragajaya, Bojonggede, Bogor; email: strameh@gmail.com
} 
in applying the Biscuit SNI (SME E) which are in zone 3; the four groups of SME that are not ready to apply the Biscuit SNI (SME D) which are in zone 4. The recommended strategy for the four groups of IKM using Ishikawa diagram which focuses on the lowest internal and external factors of resources in each SME group.

Key words: biscuit, small medium enterprises, SNI implementation strategy, zone

\section{PENDAHULUAN}

Sektor Industri pangan merupakan salah satu sektor yang mendukung visi pemerintah Indonesia yaitu Terwujudnya Indonesia yang Berdaulat, Mandiri, dan Berkepribadian Berlandaskan Gotong Royong. Dalam Rencana Induk Pembangunan Industri Nasional (RIPIN) yang merupakan pengejawantahan Undang-Undang No. 3 tahun 2014 tentang Perindustrian terdapat 10 sektor Industri Prioritas 2015-2035, dimana salah satunya sektor pangan (UU, 2014a).

Badan Standardisasi Nasional

(BSN) merupakan Lembaga Pemerintah yang bertugas dan bertanggungjawab di bidang Standardisasi dan Penilaian Kesesuaian di Indonesia. Salah satu hasil kerja BSN yaitu Standar Nasional Indonesia (SNI). SNI merupakan standar yang ditetapkan oleh BSN dan berlaku di wilayah Negara Kesatuan Republik Indonesia (UU, 2014b). Sektor Pangan juga merupakan salah satu sektor yang menjadi prioritas BSN sebagaimana tercantum pada Renstra BSN 2015-2019. Berdasarkan data yang dikeluarkan BSN pada Bulan April 2017 jumlah SNI yang telah ditetapkan BSN untuk sektor pertanian dan teknologi pangan sebanyak 2.360 SNI dari total 11.228 SNI.

Sektor Industri Kecil Menengah (IKM) memiliki peran penting dalam mendorong pertumbuhan perekonomian Indonesia. Namun perkembangan IKM di Indonesia masih dihadapkan pada berbagai persoalan sehingga menyebabkan lemahnya daya saing terhadap produk impor. Persoalan dan kendala yang dihadapi IKM, antara lain perencanaan perusahaan, keterbatasan infrastruktur, sumber daya manusia (SDM) dan jaminan mutu produk yang lebih baik (Nuraini et al. 2016). Terhadap aspek mutu produk, kendala yang dihadapi yakni UMKM kesulitan dalam memenuhi persyaratan mutu yang dipersyaratkan, dan belum semua pelaku usaha menjadikan SNI sebagai acuan dalam persyaratan mutu produknya (Kemendag, 2013).

BSN telah menetapkan SNI 2973:2011 Biskuit, dengan ruang lingkup produk yaitu Biskuit, Krekers, Wafer dan Pai, Kukis (BSN,2011). Pemberlakuan semua standar yang diberlakukan oleh BSN bersifat sukarela. Dalam hal SNI berkaitan dengan kepentingan keselamatan, keamanan, kesehatan masyarakat atau pelestarian fungsi lingkungan hidup, kementerian/lembaga pemerintah non kementerian berwenang menetapkan pemberlakuan SNI secara wajib (Pasal 24, UU No. 20 Tahun 2014). Kementerian Perindustrian selaku regulator telah memberlakukan secara wajib SNI Biskuit melalui Peraturan Menteri (Permen) Perindustrian No. 60/M-IND/PER/7/2015 yang berlaku secara efektif pada tanggal 27 Juli 2016 (Kemenperin, 2015a). Ruang lingkup peraturan tersebut mencakup untuk produk Biskuit, Krekers, Wafer dan Pai, tidak mencakup produk kukis. Selanjutnya melalui Peraturan Menteri Perindustrian No.60/M-IND/PER/7/2015 tersebut diubah dengan Peraturan Menteri No.96/M-IND/ PER/11/2015 (Kemenperin, 2015b). Namun dengan adanya masukan dan keberatan dari berbagai pihak salah satunya IKM yang memproduksi biskuit, kukis, wafer dan pai, Menteri Perindustrian menerbitkan Surat Edaran No. 500/MIND/7/2016 mengenai penundaan pemberlakuan secara wajib SNI Biskuit (Kemenperin, 2016).

Sampai saat ini jumlah industri yang yang menerapkan SNI Biskuit masih rendah dari 595 merek produk biskuit yang sudah terdaftar di BPOM (BPOM, 2017) hanya 28 merk biskuit yang telah mendapatkan sertifikat tanda SNI (BSN, 2018). Rendahnya jumlah industri yang menerapkan SNI Biskuit dipengaruhi oleh berbagai faktor diantaranya ketidaksiapan IKM dalam menerapkan persyaratan dasar penerapan SNI pangan, yaitu penerapan cara produksi pangan olahan yang baik, ketidaksiapan SDM, kesulitan dalam mengkalibrasi peralatan, distorsi produk substandar, biaya pengujian/sertifikasi yang relatif mahal dan kepedulian konsumen masih rendah.

Tujuan pengembangkan strategi penerapan SNI Biskuit bagi IKM untuk memberikan masukan IKM bagi IKM biskuit dalam menerapkan SNI, serta masukan kepada instansi teknis terkait (Kementerian Perindustrian, Kemenkop dan UKM, Pemerintahan Daerah dan BSN) dan pihak yang terkait dalam melakukan pembinaan terkait penerapan standar produk biskuit bagi IKM. 


\section{METODE PENELITIAN}

Penelitian ini dilakukan di lima IKM yang berlokasi di wilayah Bogor, Tangerang Selatan, dan Depok yang disampling dengan metode purposive sampling, dengan persyaratan bahwa IKM yang memproduksi biskuit, beromset 300 juta sampai dengan 50 milyar, dan terdata di Badan POM.

Setiap IKM dikunjungi selama dua hari dengan melakukan wawancara mendalam dengan pemilik/manajemen IKM menggunakan kuesioner tertutup, dan observasi terhadap dokumen mutu, lokasi proses produksi dengan mengisi kuesioner checklist yang telah disusun dengan metode skoring. Kuesioner penilaian IKM Biskuit disusun dengan melihat faktor sumber daya yang memengaruhi IKM berdasarkan persyaratan yang harus dipenuhhi IKM dalam menerapkan SNI Biskuit yaitu: Man (manusia); Materials (materi); Machines (mesin-mesin); Methods (tata kerja); Money (uang); Markets (pasar); Management (manajemen), Environment (lingkungan).

Pengukuran kesiapan IKM dalam menerapkan SNI Biskuit menggunakan sistem skoring dengan skala 0-4. Nilai 0 diberikan bila aspek penilaian tidak tersedia di IKM, nilai 1 diberikan bila kondisi pernyataan negatif beresiko besar bagi IKM, nilai 2 diberikan bila kondisi pernyataan negative beresiko sedang bagi IKM, nilai 3 diberikan bila kondisi pernyataan negative beresiko kecil bagi IKM, nilai 4 diberikan bila pernyataan negative tidak terdapat di IKM. Hasil penilaian terendah terendah adalah 0 dan nilai tertinggi adalah 580. Hasil dari penilaian setiap IKM dinyatakan dalam pesentase untuk memudahkan melihat tingkat kesiapannya dalam menerapkan SNI.

Berdasarkan jumlah skor yang diperoleh IKM, selanjutnya dilakukan pengelompokkan IKM dengan menggunakan metode statistika. Dari lima IKM ditentukan nilai rata-rata (mean) dan simpangan baku (standar deviasi). Selanjutnya IKM dikelompokkan dalam empat zona yaitu:

a) Zona satu

IKM dengan tingkat kesiapan sama atau lebih dari nilai rata-rata ditambah dengan standar deviasi, yang disebut sebagai kelompok IKM yang siap dalam menerapkan SNI Biskuit

b) Zona dua

IKM dengan tingkat kesiapan antara nilai ratarata sampai dengan nilai kurang dari rata-rata ditambah dengan standar deviasi, yang disebut sebagai kelompok IKM yang cukup siap dalam menerapkan SNI Biskuit.

c) Zona tiga

IKM dengan tingkat kesiapan dari nilai ratarata dikuringi standar deviasi sampai dengan nilai kurang dari rata-rata, yang disebut sebagai kelompok IKM yang kurang siap dalam menerapkan SNI Biskuit.

d) Zona empat

IKM dengan tingkat kesiapan kurang dari nilai rata-rata dikurangi standar deviasi yang disebut sebagai kelompok IKM yang tidak siap dalam menerapkan SNI Biskuit.

\section{HASIL DAN PEMBAHASAN}

Penelitian dilakukan pada lima IKM yang memproduksi biskuit dengan kondisi umum berikut:

1. IKM A

IKM A berlokasi di wilayah Tangerang Selatan, dengan lokasi produksi terpisah dengan rumah pemilik. IKM A dikelompokkan sebagi industri kecil yang memiliki karyawan lima orang. IKM ini telah memiliki izin legalitas dari pemerintah daerah dan dinas perindustrian perdagangan setempat. IKM A telah mendapatkan izin edar Merk Dalam Negri (MD) dari Badan POM. Pemasaran produk biskuit IKM A mencakup wilayah Jakarta, Bogor, Depok, Tangerang, dan Bekasi, serta Surabaya. IKM A memiliki tingkat kesiapan dengan penilaian yang tinggi yaitu sebesar $97,4 \%$. Hasil penilaian terhadap faktor sumber daya tertinggi ada pada faktor sumber daya bahan baku dan sumber daya manusia masing-masing sebesar $100 \%$. Hal ini disebabkan beberapa faktor diantaranya IKM A secara konsisten menggunakan tepung terigu dan margarin yang sudah memenuhi SNI, IKM A telah menggunakan sistem kartu dalam penyimpanan bahan baku, serta IKM A secara konsisten selalu menjaga kompetensi karyawan, kesehatan dan sanitasi karyawannya. Adapun faktor sumber daya mencapai nilai terendah yaitu faktor sumber daya keuangan sebesar $88 \%$.

2. IKM B

IKM B berlokasi di wilayah Bogor, dengan lokasi produksi terpisah dengan rumah pemilik. IKM B dikelompokkan sebagi industri kecil yang memiliki karyawan tujuh orang. IKM ini telah memiliki izin legalitas dari pemerintah daerah dan dinas perindustrian 
perdagangan setempat. IKM B juga telah mendapatkan izin edar PIRT dari Dinas Kesehatan. Pemasaran produk biskuit IKM B mencakup wilayah Jakarta, Bogor, Depok, Tangerang, dan Bekasi. Penilaian terhadap faktor sumber daya IKM B memiliki tingkat kesiapan dengan rataan yang cukup tinggi yaitu $84,5 \%$. Hasil penilaian terhadap faktor sumber daya tertinggi ada pada bahan baku sebesar $100 \%$. Hal ini disebabkan beberapa faktor, dimana IKM secara konsisten menggunakan tepung terigu dan margarin yang sudah memenuhi SNI, IKM A telah menggunakan sistem kartu dalam penyimpanan bahan baku. Adapun penilaian faktor sumber daya terendah ada pada faktor sumber daya keuangan sebesar $68 \%$.

\section{IKM C}

IKM C berlokasi di wilayah Bogor, dengan lokasi produksi di rumah pemilik. IKM C dikelompokkan sebagi industri kecil yang memiliki karyawan lima orang. IKM ini telah memiliki izin legalitas dari pemerintah daerah dan dinas perindustrian perdagangan setempat. IKM C juga telah mendapatkan izin edar Produk Industri Rumah Tangga (PIRT) dari Dinas Kesehatan. Pemasaran produk biskuit IKM C mencakup wilayah Jakarta, Bogor, Depok. Penilaian terhadap faktor sumber daya IKM C memiliki tingkat kesiapan dengan rataan yang cukup tinggi yaitu $83,6 \%$. Hasil penilaian terhadap faktor sumber daya tertinggi ada pada bahan baku sebesar $100 \%$, hal ini disebabkan beberapa faktor diantaranya secara konsisten menggunakan tepung terigu dan margarin yang sudah memenuhi SNI. Adapun penilaian faktor sumber daya terendah ada pada faktor sumber daya manajemen sebesar $71 \%$.

4. IKM D

IKM D berlokasi di wilayah Depok, dengan lokasi produksi terpisah dengan rumah pemilik. IKM D dikelompokkan sebagi industri kecil yang memiliki karyawan lima orang. IKM ini telah memiliki izin legalitas dari pemerintah daerah dan dinas perindustrian perdagangan setempat. Pemasaran produk biskuit IKM D mencakup wilayah Depok, Bogor. Penilaian terhadap faktor sumber daya IKM D memiliki tingkat kesiapan dengan penilaian yang rendah yaitu $62,9 \%$. Hasil penilaian terhadap faktor sumber daya tertinggi ada pada bahan baku sebesar $82 \%$, penilaian faktor sumber daya terendah ada pada faktor sumber keuangan sebesar $56 \%$.

5. IKM E

IKM E berlokasi di wilayah Bogor, dengan lokasi produksi di rumah pemilik. IKM E dikelompokkan sebagi industri kecil yang memiliki karyawan lima orang. IKM ini telah memiliki izin legalitas dari pemerintah daerah dan dinas perindustrian perdagangan setempat. Pemasaran produk biskuit IKM E mencakup wilayah Bogor, Depok. Penilaian terhadap faktor sumber daya IKM E memiliki tingkat kesiapan dengan penilaian yang cukup rendah yaitu $71 \%$. Hasil penilaian terhadap faktor sumber daya tertinggi ada pada bahan baku sebesar $85 \%$, adapun penilaian faktor sumber daya terendah ada pada faktor sumber daya keuangan sebesar $66 \%$.

Hasil penilaian kesiapan lima IKM dalam menerapkan SNI 2973:2011 diperoleh data bahwa IKM A memiliki persentase sebesar 97,4\%, IKM B $84,5 \%$, IKM C 83,6\%, IKM D 62,9\%, dan IKM E $71,4 \%$, sebagaimana dapat dilihat pada Gambar 1

Hasil penilaian kelima IKM terhadap kesiapan faktor sumber daya manusia (man), bahan baku (materials), mesin dan peralatan (machines and tools), metoda (methods), uang (money), pasar (markets), lingkungan (environtment) dalam menerapkan SNI Biskuit dapat dilihat pada Gambar 2.

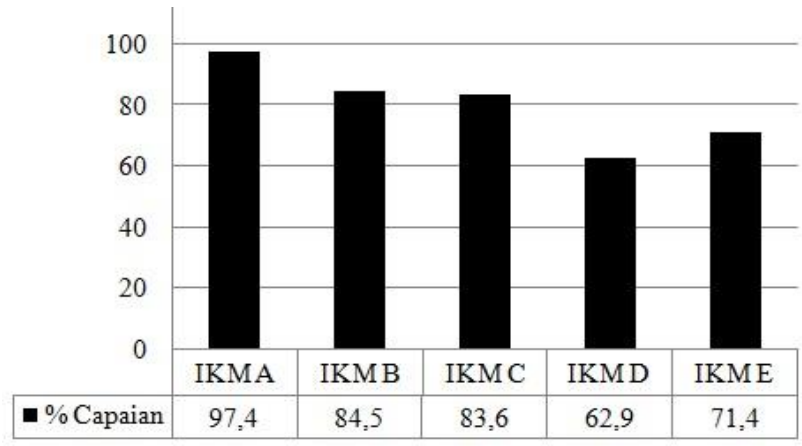

Gambar 1. Persentase tingkat kesiapan IKM 


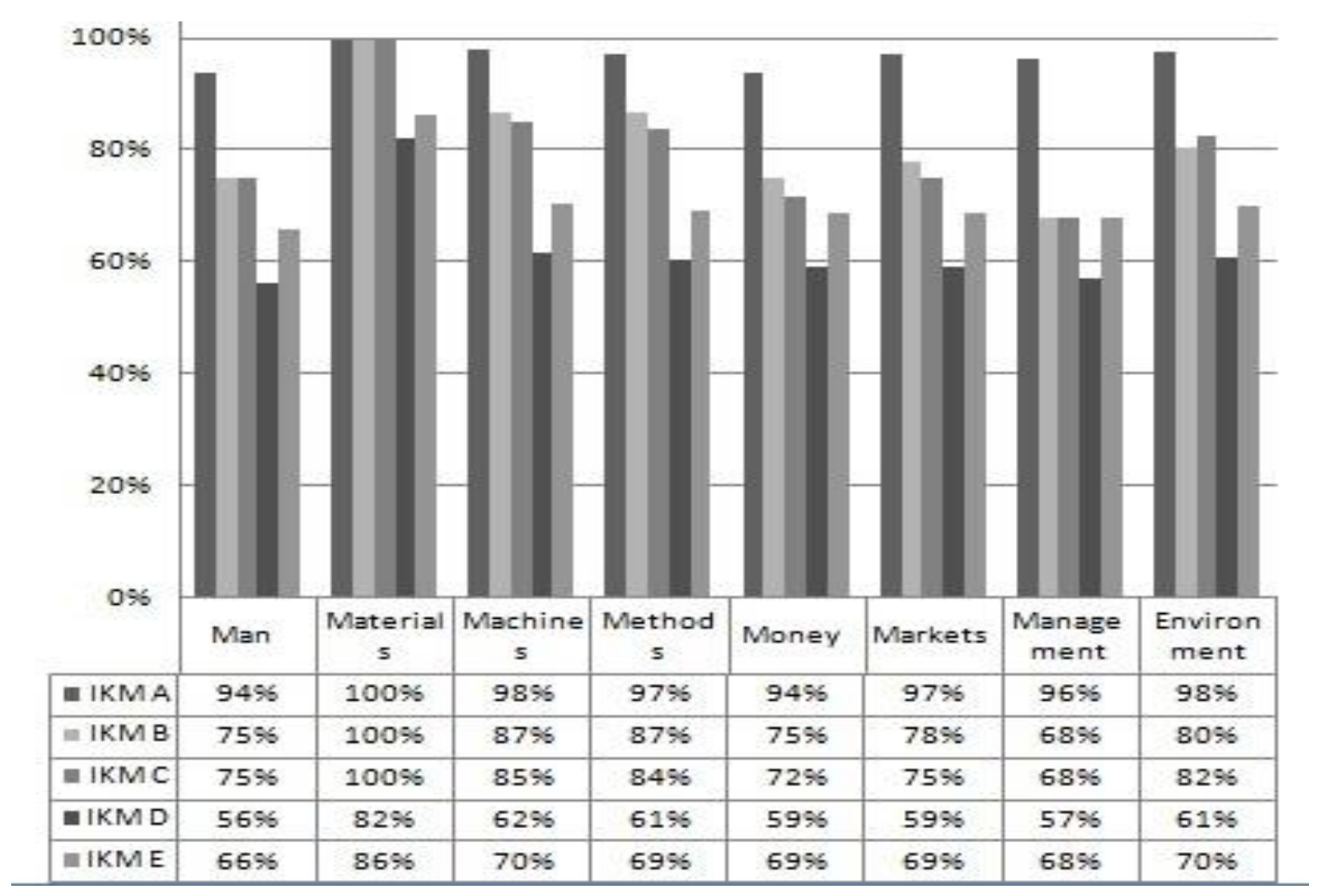

Gambar 2. Kesiapan faktor sumber daya IKM dalam menerapkan SNI biskuit

Selanjutnya dilakukan pengelompokkan IKM dengan analisa statistik terhadap hasil penilaian dari lima IKM. Pertama dilakukan pengukuran rata-rata (mean) dengan simbol ' $x$ ", dari hasil penilaian kesiapan lima IKM dalam penerapan SNI diperoleh rata-rata sebesar $80 \%$. Selanjutnya dilakukan pengukuran nilai simpangan baku (standar deviasi) dengan simbol 's" sebesar 13. Berdasarkan nilai rata-rata dan simpangan baku dibuat empat zona kesiapan IKM dalam menerapkan SNI biskuit. Berdasarkan pengelompokkan IKM tersebut maka IKM A berada pada kelompok IKM yang sangat siap dalam menerapkan SNI Biskuit, IKM B dan IKM C berada pada kelompok IKM yang siap dalam menerapkan SNI Biskuit, IKM E berada pada kelompok IKM yang kurang siap dalam menerapkan SNI Biskuit dan IKM E berada pada kelompok IKM yang tidak siap dalam menerapkan SNI Biskuit. Zonasi IKM selengkapnya dapat dilihat pada Tabel 1.

Tabel 1. Zona IKM

\begin{tabular}{ccc}
\hline Zona & $\begin{array}{c}\text { Persentase nilai } \\
\text { IKM }(\%)\end{array}$ & $\begin{array}{c}\text { Tingkat kesiapan } \\
\text { kelompok (TKK) }\end{array}$ \\
\hline Zona 1 & $\leq 93-100$ & Siap \\
Zona 2 & $\leq 80-<93$ & Cukup siap \\
Zona 3 & $\leq 67-<80$ & Kurang siap \\
Zona 4 & $<67$ & Tidak siap \\
\hline
\end{tabular}

Selanjutnya dilakukan pengembangan strategi bagi keempat kelompok IKM menggu- nakan diagram ishikawa, dengan mempertimbangkan tingkat kesiapan setiap faktor sumber daya IKM. Tingkat kesiapan kelompok IKM berdasarkan masing-masing fakor sumber daya dapat dilihat pada Tabel 2. Pengembangan strategi difokuskan pada usaha untuk memperbaiki sumber daya internal dan eksternal dengan tingkat kesiapan terendah. Diagram ishikawa dapat dilihat pada Gambar 3.

Strategi yang direkomendasikan bagi setiap kelompok, yaitu:

1. Kelompok IKM yang siap dalam menerapkan SNI Biskuit

Kelompok IKM siap dalam menerapkan SNI berada pada rentang yang tinggi. IKM yang ada pada kelompok ini memiliki tingkat kesiapan lebih dari 93\%. Tingkat kesiapan sumber daya tertinggi ada pada bahan baku dan manusia sebesar $100 \%$, dan kesiapan terendah $88 \%$ untuk keuangan. Strategi yang direkomendasikan pada kelompok ini berdasarkan tingkat kesiapan sumber daya terendah, dalam hal ini sumber daya keuangan. Strategi yang direkomendasikan bagi IKM pangan olahan biskuit pada kelompok ini, yaitu peningkatan modal usaha. Usaha untuk meningkatkan kapasitas modal dapat dilakukan dengan memanfaatkan jasa perbankan, menjalin kerjasama dengan lembaga keuangan lainnya. 
2. Kelompok IKM yang cukup siap dalam menerapkan SNI Biskuit

Kelompok IKM cukup siap dalam menerapkan SNI berada pada rentang yang cukup tinggi. Dimana IKM yang ada pada kelompok ini memiliki tingkat kesiapan sama dengan atau lebih dari $80 \%$ sampai dengan 93\%. Strategi bagi kelompok IKM yang cukup siap dalam menerapkan SNI sebagai berikut: meningkatkan kemampuan mengelola keuangan dengan mengikuti pelatihan; meningkatkan kemampuan manajemen SDM mengikuti berbagai pelatihan; dan meningkatkan modal dengan menjalin kerjasama dengan lembaga keuangan atau koperasi.

3. Kelompok IKM yang kurang siap dalam menerapkan SNI Biskuit

Kelompok IKM kurang siap dalam menerapkan SNI berada pada rentang yang cukup rendah. Dimana IKM yang ada pada kelompok ini memiliki tingkat kesiapan sama dengan atau lebih dari $67 \%$ sampai dengan $80 \%$. Strategi yang direkomendasikan bagi kelompok IKM yang kurang siap dalam menerapkan SNI, yaitu meningkatkan kemampuan dan kompetensi dalam mengelola keuangan dengan mengikuti pelatihan; meningkatkan kemampuan manajemen dalam mengelola SDM dengan mengikuti pelatihan; memastikan semua produk biskuit yang diproduksi memenuhi standar; konsisten mendokumentasikan operasionalisasi program cara produksi pagan olahan yang baik; dan meningkatkan modal dengan menjalin kerjasama dengan lembaga keuangan atau koperasi.

Tabel 2. Tingkat kesiapan faktor sumber daya setiap kelompok IKM

\begin{tabular}{llcccc}
\hline \multirow{2}{*}{ No. } & \multirow{2}{*}{ Sumber daya } & \multicolumn{4}{c}{ Kelompok IKM (\%) } \\
\cline { 3 - 6 } & & Siap & Cukup siap & Kurang siap & Tidak siap \\
\hline 1 & Manusia & 100 & 83 & 58 & 71 \\
2 & Bahan baku & 100 & 100 & 82 & 85 \\
3 & Mesin dan peralatan & 98 & 86 & 62 & 70 \\
4 & Metode & 97 & 85 & 61 & 69 \\
5 & Keuangan & 88 & 72 & 56 & 66 \\
6 & Pemasaran & 97 & 75 & 59 & 69 \\
7 & Manajemen & 96 & 73 & 57 & 68 \\
8 & Lingkungan & 98 & 81 & 61 & 70 \\
\hline
\end{tabular}

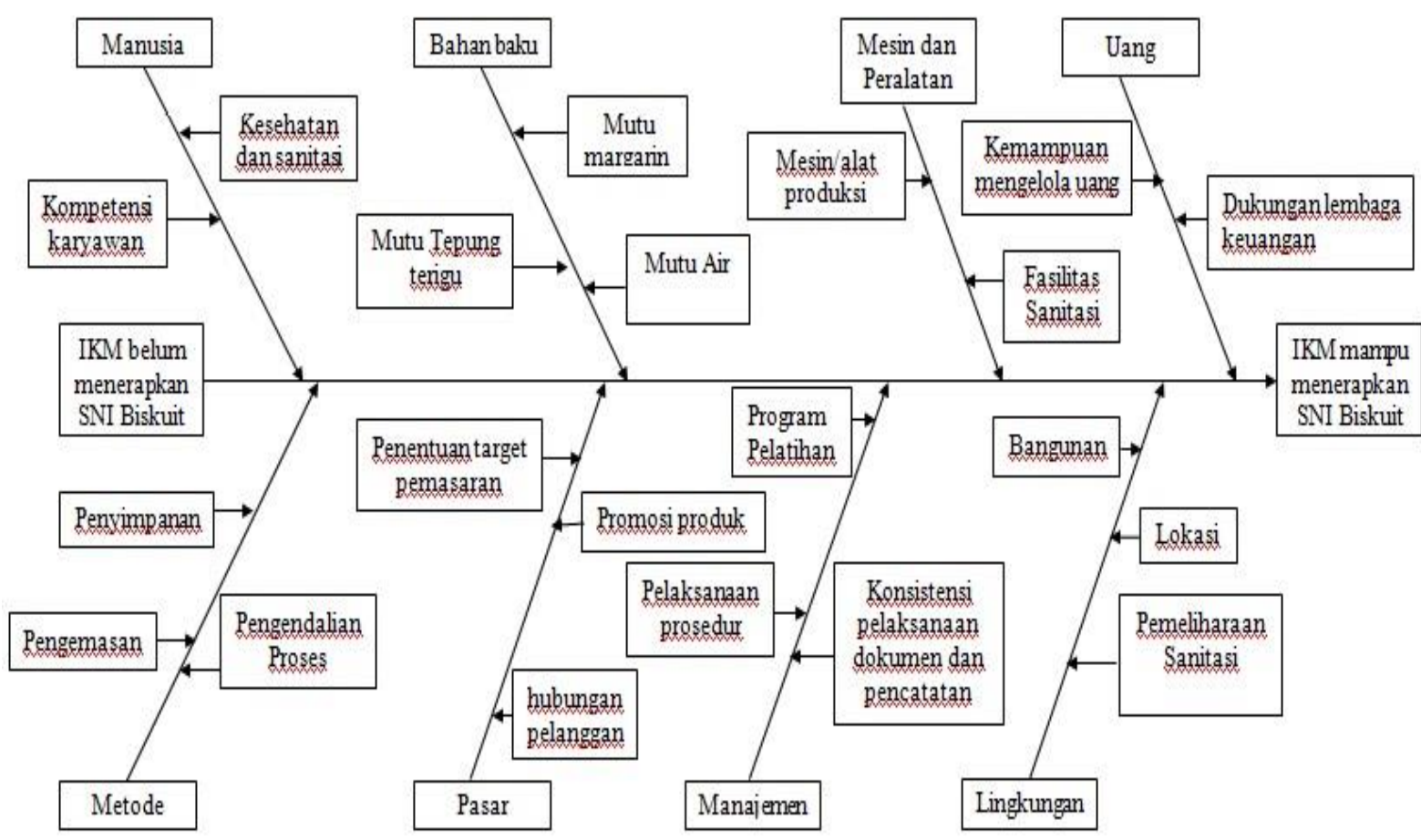

Gambar 3. Diagram Ishikawa strategi penerapan SNI biskuit 
4. Kelompok IKM yang tidak siap dalam menerapkan SNI Biskuit

Dimana IKM yang ada pada kelompok ini memiliki tingkat kesiapan kurang dari 67\%. Strategi yang direkomendasikan bagi IKM yang berada pada kelompok IKM yang berada pada kelompok ini sebagai berikut: meningkatkan kemampuan dan kompetensi dalam mengelola keuangan; meningkatkan kemampuan manajemen SDM dengan mengikuti pelatihan; IKM memastikan semua produk biskuit yang diproduksi memenuhi standar; IKM secara konsisten mendokumentasikan operasionalisasi program cara produksi pangan olahan yang baik; IKM perlu meningkatkan kompetensi karyawan dalam menerapkan cara produksi pangan olahan yang baik dengan mengikuti berbagai pelatihan; dan meningkatkan modal usaha.

\section{KESIMPULAN}

Kesiapan lima IKM dalam menerapkan SNI 2973:2011 secara berturut-turut sebagai berikut IKM A 97,4\%; IKM B 84,5\%; IKM C 83,6\%; IKM D $62,9 \%$; dan IKM E 71,4\%. Hasil pengelompokan kelima IKM diperoleh empat kelompok IKM yaitu pertama kelompok yang sangat siap dalam menerapkan SNI Biskuit (IKM A) yang berada pada zona satu, kedua kelompok yang siap dalam menerapkan SNI Biskuit (IKM B dan C) yang berada pada zona dua, ketiga kelompok IKM yang kurang siap dalam menerapkan SNI Biskuit (IKM E) yang berada pada zona tiga, keempat kelompok IKM yang tidak siap dalam menerapkan SNI Biskuit (IKM D) yang berada pada zona empat. Strategi yang direkomendasikan bagi keempat kelompok IKM berfokus pada faktor internal dan eksternal sumber daya terendah di setiap kelompok IKM.

\section{DAFTAR PUSTAKA}

Athena IS. 2011. Supply chains; Packaged goods; Manufacturers; Materials management; Small \&medium sized enterprises-SME. Financial Express New Delhi 11 July 2011

Austrian Standards, 2017. ISO and SMEs. [Internet] [dapat diunduh dari https://www. austrian-standards.at/en/products-services/ managing-standards-professionally/weitereinformationen-speziell-fuer-ihrenbedarf/small-medium-sized-enterprises/
[BPOM] Badan Pengawas Obat dan Makanan. 2017. Produk biskuit terdaftar di Badan Pengawas Obat dan Makanan. [Internet] [dapat diunduh dari http://cekbpom.pom. go.id/index.php/home/produk/48e4b24dd09 efb21bfcd7ba156ff3641/all/row/100/page/1/o rder/4/DESC/search/1/biskuit]

[BSN] Badan Standardisasi Nasional. 2011. Standar Nasional Indonesia Biskuit SNI 2973:2011. BSN. Jakarta (ID) : BSN

2011c. Rekomendasi Nasional KodePraktis - Prinsip umum higiene pangan SNI CAC/RCP 1:2011. BSN. Jakarta (ID): BSN. 2018. Biskuit ber SNI. [Internet] [dapat diunduh dari http://bangbeni.bsn.go.id/\#!/ barang-ber-sni]

[CAC] Codex Alimentarius Commission. 2003. Recommended International Code of Practice General Prionciple of Food Hygiene CAC/RCP 1-1969, Rev. 4(2003). CAC. Rome (IT) : CAC

Cumbers, A., R. Leigh, D. Smallbone. 1995. The Single European Market and the new regulatory regime in the food sector: The impact on small and medium-sized manufacturing firms. British Food Journal: Bradford 97.4 (1995): 13

David, F.R. 2010. Konsep Manajemen Strategis (Terjemahan). Jakarta: Salemba Empat.

Haryotejo, B. 2013. Faktor-Faktor Yang Memengaruhi Produsen Mie Instan dalam Penerapan Standar Nasional Indonesia. Litbang Perdagangan, 7(1): 111-127

Herjanto, E. 2011. Pemberlakuan SNI Secara Wajib Di Sektor Industri: Efektifitas Dan Berbagai Aspek Dalam Penerapannya. Jurnal Riset Industri, V(2): 121-130.

Gasperz, V. 2003. Total Quality Management. Cetakan ketiga. PT Gramedia Pustaka Utama. Jakarta

Hubeis, M. 2007. Dasar-Dasar Manajemen. Jakarta: Inti Prima

, M. Najib, 2008. Manajemen Strategik dalam Pengembangan Daya Saing Organisasi. Jakarta: PT Elex Media Komputindo.

[Kemendag] Laporan Akhir Kementerian Perdagangan. 2013. Kajian Kebutuhan Standar dalam Dimensi Daya Saing dan Perlindungan Konsumen. Jakarta (ID): Kemendag

Moneim, A.E., Sulieman, H.M. Siddeg, Z.A. Salih. 2013. The Design of Hazard Analysis Critical Control Point (HACCP) Plan for Biscuit Plant. Food and Public Health 2013, 3(5): 240-246. 
Nuraini, F., R. Maharani, Andrianto. 2016. Strategi Peningkatan Daya Saing UMKM dan Koperasi dalam menghadapi MEA. Prosiding Seminar Nasional Ekonomi dan Bisnis FEB UMSIDA: 480-496.

Soeprapto, F. 2009. Penilaian GMP dan SSOP pada Bagian Pengolahan Makanan di Katering $X$ Surabaya dengan Metode Skoring sebagai Prasyarat Penerapan HACCP. The Indonesian Journal of Public Health, 6(1): 30-37.

UNIDO, 2013. A guide for small and medium enterprices on the value of standard conformance. Austria: UNIDO.
[UU]. Undang-Undang Republik Indonesia. 2008. Undang-Undang No.20 Tahun 2008 tentang Usaha Mikro, Kecil, Menengah

[UU]. Undang-Undang Republik Indonesia. 2012. Undang-Undang No. 8 tahun 2012 tentang Pangan

[UU]. Undang-Undang Republik Indonesia. 2014a. Undang-Undang No. 3 tahun 2014 tentang Perindustrian

[UU]. Undang-Undang Republik Indonesia. 2014b. Undang-Undang No.20 Tahun 2014 tentang Standardisasi 